\title{
Cartografando estilizações do homoerotismo na velhice: pistas metodológicas nos estudos sobre sexualidades ${ }^{\star}$
}

\author{
Daniel Kerry dos Santos, Mara Coelho de Souza Lago $\star \star$ \\ Universidade Federal de Santa Catarina, Florianópolis, SC, Brasil
}

Resumo

\begin{abstract}
Esse artigo problematiza a cartografia como possibilidade metodológica em pesquisas sobre sexualidades. A partir da aproximação entre algumas perspectivas dos estudos de gênero e queer e o pensamento cartográfico proposto por Gilles Deleuze e Félix Guattari, procura-se destacar pontos em comum entre essas abordagens. Após uma introdução que procura aproximar tais vertentes, apresentam-se algumas notas de pesquisa de campo onde se cartografou modos de estilização do homoerotismo na velhice entre homens num bar na cidade de Florianópolis (SC, Brasil). Procurou-se enfatizar os efeitos do/no corpo do pesquisador (de afetar e ser afetado) no processo de habitar tal território de sociabilidade.
\end{abstract}

Palavras-chave: cartografia; sexualidade; homoerotismo; velhice; metodologia de pesquisa.

\section{Cartographying stylizations of the homoerotism in the old age: methodological clues in sexuality studies}

\begin{abstract}
This paper problematizes cartography as a methodological possibility on research about sexualities. Bringing together some gender studies and queer perspectives and the cartographic thinking proposed by Gilles Deleuze and Félix Guattari, it attempts to stress common grounds among these approaches. After an introduction that aims to approximate such strands, it presents some fieldwork notes of a research that aimed to cartography ways of stylizations of the homoeroticism in the old age among men in a bar in the city of Florianópolis (SC, Brazil). The text also emphasizes the effects of/on the researcher's body (of affecting and being affected) during the process of inhabiting such sociability territory.
\end{abstract}

Keywords: cartography; sexuality; homoeroticism; old age; research methodology.

\section{Introdução: localizando algumas linhas}

Em nossas pesquisas recentes temos problematizado algumas formas pelas quais o homoerotismo e a homossexualidade ${ }^{1}$ podem ser experienciados, estilizados e performatizados na velhice (SANTOS, 2012; SANTOS; LAGO, 2012, 2013). Buscamos por cartografias que sinalizassem como o desejo, o corpo e o erotismo

\footnotetext{
$\star$ Fonte de financiamento: CAPES

$\star \star$ Endereço para correspondência: Universidade Federal de Santa Catarina, Centro de Filosofia e Ciências Humanas, Departamento de Psicologia. Campus Universitário s/n. Trindade. CEP: 88040900 - Florianópolis, SC - Brasil Caixa-postal: 476. E-mail: dakerry@gmail.com,maralago7@gmail.com

${ }^{1}$ Durante nosso texto usamos os termos homoerotismo e homossexualidade, mas consideramos algumas diferenças, ainda que sutis, entre ambos. Concordamos com Jurandir Freire Costa (1992, p. 21) quanto ao fato de que o termo homoerotismo seria uma noção "mais flexível e que descreve melhor a pluralidade das práticas ou desejos dos homens "same-sex oriented"". O termo homoerotismo, segundo o autor, procura se distanciar de noções de que existiria uma "substância", uma "estrutura", uma "essência" ou um "denominador comum" da homossexualidade. Costa, J. defende o uso do termo homoerotismo como uma forma de se afastar de qualquer alusão à doença, ao desvio, à anormalidade e/ou à perversão, categorias estas que foram historicamente associadas às pessoas homoeroticamente orientadas. $\mathrm{O}$ autor refere-se ao homoerotismo como meramente a "possibilidade que têm certos sujeitos de sentir diversos tipos de atração erótica ou de se relacionar fisicamente de diversas maneiras com outros do mesmo sexo biológico" (COSTA, J., 1992, p. 22). Por outro lado, entendemos que o termo "homossexualidade" tem uma função discursiva identitária importante que não pode ser menosprezada. Se a homossexualidade é um tipo de discurso moderno e sócio-historicamente localizável, como nos mostrou Foucault (1988), e se os discursos constituem posicionalidades de sujeito, não podemos negar que essas posições produzem identidades a partir das quais os sujeitos se localizam. Apesar de o termo "homossexualidade" ter surgido dentro de um contexto médico-sexológico, hoje o mesmo termo está muito mais associado a uma "posição de afirmação política" ou a "estilos de vida". Assim, podemos pensar em modos de vida e em formas de reinvenção do próprio homoerotismo a partir da experiência e vivência da homossexualidade, algo próximo ao que sugere Foucault (1981) em seu texto "Da amizade como modo de vida": "Quais relações podem ser estabelecidas, inventadas, multiplicadas, moduladas através da homossexualidade?" O problema não é o de descobri em si a verdade sobre seu sexo, mas, mais importante que isso, usar, daí em diante, de sua sexualidade para chegar a uma multiplicidade de relações".
}

se agenciam e se (co)produzem, mesmo diante de alguns fantasmas de abjeção que rondam as existências de sujeitos que corporificam as marcas do tempo e que experienciam uma sexualidade não-heterossexual.

A velhice entre sujeitos que se reconhecem e se afirmam como homossexuais/gays ainda pode ser, em alguns contextos, vista como a expressão de uma vida fora de um "mercado sexual" ou mesmo como uma caricatura de um corpo abjeto ou despotencializado, como denunciam alguns autores (MOTA, 2009; SIMÕES, 2004; PAIVA, 2009). Estamos diante de pelo menos duas linhas de estratificação: o corpo enunciado como velho, que se constitui a partir do dispositivo da idade (POCAHY, 2011) e que está eminentemente organizado e circunscrito em enunciados biopolíticos; e a sexualidade, que além de também estar regulada pela biopolítica contemporânea, constitui-se pela regulação da heteronormatividade. Assim, temos considerado que sujeitos interpelados como "velhos" e que se autodeterminam "homossexuais" e/ou que experienciam modos de vida não-heterossexuais têm de se confrontar com uma matriz heterossexual e com um valor de juventude socialmente produzido como um ideal regulatório (que é inclusive o que pode valorar positivamente as experiências da homossexualidade). Diante desses imperativos, a velhice considerada inteligível é pressuposta como heterossexual e a homossexualidade dita "aceita" é inscrita nas marcas do que se entende por "jovem". Nesses termos, o "velho gay" tensiona o jogo das representações normativas sobre a velhice (sempre 
heterossexual) e sobre a homosexualidade (sempre jovem, de corpos torneados, branca, de classe média, com poder de consumo, etc.).

Ainda que esses modos de objetivação dos sujeitos estejam colados aos planos de estratificação que homogeneízam os corpos e as subjetividades, algumas pesquisas vêm mostrando que a existência não se deixa capturar o tempo todo por essas significações totalizantes (SIMÕES, 2004; POCAHY, 2011; HENNING, 2014). O (homo)erotismo, o sexo e o corpo se engatam em linhas de fuga, percorrem meios e se produzem em territórios outros, nas heterotopias, como diria Foucault (2009), ou nesses territórios alternativos, como propõe Perlongher (2005). Fundem-se, se encontram, se afetam e se movimentam em saunas, bares, internet, parques, ruas e mesmo em espaços privados de intimidade, de modo que os corpos e o desejo possam encontrar matérias de expressão. Algo escapa do campo das representações, das significações e das totalizações e foi esse "algo" fugidio e processual que buscamos seguir em nossas cartografias.

Tivemos a intenção de acompanhar as fissuras e os momentos disruptivos testemunhados a partir de um território de sociabilidade e das narrativas de alguns interlocutores com os quais pudemos dialogar. Espreitávamos aquelas porosidades que deixam fluir potências desejantes entre corpos, ainda que estes estejam sujeitos a um regime de significação totalizante, serializante e massificador. Para acompanhar esses processos, fomos traçando cartografias a partir de um território de sociabilidade frequentado principalmente por homens cisgêneros de "mais idade" (que em espaços de sociabilidades gays mais hegemônicos seriam considerados "velhos"), que se autodefinem como gays, bissexuais e/ou que experienciam práticas homoeróticas (ainda que não se identifiquem com nenhuma dessas identidades). Tal território se constitui em um "Bar de Ursos", ${ }^{2}$ localizado em região periférica de Florianópolis (SC). Ao traçar essa cartografia, habitou-se esse território de sociabilidade, seguindo a pista de Alvarez e Passos (2009) que sugere que "cartografar é habitar um território existencial". Habitar um território de sociabilidade significou mais do que apenas frequentar o bar, descrever densamente o que lá ocorria e buscar algum tipo de representação totalizada sobre o local. Foi necessário um processo de abertura, afecção, aprendizagem de outros signos de expressão da sexualidade e do erotismo que não eram aqueles com os quais o cartógrafo estava mais familiarizado - como será apresentado ao final deste texto.

Algumas de nossas problematizações decorrentes dessas cartografias foram discutidas em outras publicações, onde focamos especificamente nos afetos estéticos, na corporeidade e na produção desejante mobilizada em tal território (SANTOS; LAGO, 2012), bem como nas narrativas compartilhadas entre alguns interlocutores da pesquisa e o cartógrafo (SANTOS; LAGO, 2013). O que

${ }^{2}$ Ursos (ou Bears, em inglês) é uma categoria identitária que se refere, geralmente, a homens gordos, peludos e barbudos, que sentem atração por outros homens (ursos também, ou não). No entanto, a categoria "ursos" é bastante genérica e pode englobar uma multiplicidade de corpos bem diferentes (por exemplo: ursos velhos, ursos jovens, ursos gordos peludos, ursos gordos lisos, etc.). Uma única definição, portanto, seria insuficiente para representá-los. gostaríamos de focar nesse texto, no entanto, são algumas de nossas reflexões metodológicas acerca do uso da cartografia em pesquisas sobre sexualidade. Os diálogos entre as perspectivas dos estudos de gênero e queer e o princípio da cartografia foram sendo desenvolvidos ao longo de nossas investigações, de modo que pudemos vislumbrar conexões potentes entre esses campos de estudos. Ansiamos colaborar com pistas possíveis do método da cartografia, sobretudo em pesquisas na área da psicologia social que buscam acompanhar expressões daquilo que se chama de "sexualidades desviantes" ou, ainda, aquelas sexualidades que ocupam um lugar de marginalidade, ininteligibilidade e ilegitimidade no imaginário social. Não pretendemos esgotar as possibilidades de aproximações e tensões entre essas diferentes perspectivas teóricas, mas ensaiar algumas possibilidades de conexões.

\section{Perspectivas de gênero, queer e a cartografia: introduzindo uma breve aproximação}

Para falar de cartografia como "metodologia" é necessário suspender algumas concepções clássicas da noção de método e de epistemologia da ciência. Para estas, o conhecimento é produzido a partir de uma ação ativa do sujeito cognoscente sobre um objeto pronto a espera de ser desvelado. Há uma nítida separação entre sujeito (transcendente, universal e a-histórico) e objeto (natural, acabado e imutável). Segundo Prado-Filho (2006, p. 23) "o sujeito da epistemologia tradicional é o sujeito transcendental kantiano, que no exercício de sua razão, apropria-se das regras de produção do conhecimento e, aplicando-as adequadamente, produz uma verdade confiável sobre o objeto". Diferentemente das correntes indutivistas e experimentais, existem também as correntes relativistas, as quais visam relativizar o primado do sujeito racional e de suas verdades, mas que, no entanto, buscam uma "reforma" da ciência, de modo que a mesma continua ocupando seu espaço privilegiado de produção do saber. Prado-Filho (2006) aponta, no entanto, que Nietzsche e Foucault estabelecem uma ruptura radical na ciência, ${ }^{3}$ problematizando seus regimes de verdade e as relações de poder que emanam de saberes científicos datados historicamente. Este autor irá defender que há no pensamento de Nietzsche e Foucault uma contra-epistemologia que definirá o que se pode chamar de olhar "perspectivista", o qual "[...] não tenta substituir uma verdade por outra 'melhor' ou 'mais objetiva', mas coloca-se no jogo do discurso como visada histórica possível entre outras" (PRADO-FILHO, 2006, p. 29).

É nessa mesma linha perspectivista que podemos situar os princípios cartográficos tais como propostos por Gilles Deleuze e Félix Guattari (2009). Como diria Guattari (1992) a existência e o ser não são unívocos, portanto não podemos reduzi-los a signos, significados, significantes, símbolos ou qualquer forma de representação totalizante. "A existência não é dialética, não é representável. Mal se consegue vivê-la!” (GUATTARI, ${ }^{3}$ É importante salientar que não somente Nietzsche e Foucault estabelecem uma
ruptura nos sistemas de pensamento ocidentais, mas várias correntes teóricas
que se posicionaram contra uma ciência moderna positivista, racionalista
e utilitarista, dentre elas algumas linhas da psicanálise, do marxismo, dos feminismos, entre outras.

Fractal, Rev. Psicol., v. 27 - n. 2, p. 95-106, 2015 
1992, p. 66). Frente a essa problemática, o mesmo autor sugere que optemos por uma escolha ética crucial: “ou se objetiva, se reifica, se 'cientificiza' a subjetividade, ou ao contrário, tenta-se apreendê-la em sua dimensão de criatividade processual" (GUATTARI, 1992, p. 24). Um olhar cartográfico sobre as sexualidades e as subjetividades deve procurar se basear na segunda opção, a partir da qual se pode atribuir à subjetividade um possível caráter processual e estético, ou seja, passível de ser constantemente (re)criada e (re)inventada. É nesse sentido que Guattari (1992, p. 24) irá se posicionar ante à noção de cartografia como método:

[...] não considero minhas 'cartografias esquizo-analíticas' como doutrinas científicas [...] o importante nesse caso não é o resultado final mas o fato de o método cartográfico multicomponencial coexistir com o processo de subjetivação e de ser assim tornada possível uma reapropriação, uma autopoiese, dos meios de produção de subjetividade.

Seguindo tais proposições ético-filosóficas de descentrar o sujeito na hieraquia da produção de conhecimento, Passos e Benevides (2009, p. 17) propõem uma reversão etimológica do "método" (metá = reflexão, raciocínio, verdade e hódos = caminho, direção). Tal reversão, segundo os autores, "afirma um hódos-metá. A diretriz cartográfica se faz por pistas que orientam o percurso da pesquisa sempre considerando os efeitos do processo do pesquisador sobre o objeto da pesquisa, o pesquisador e seus resultados" (PASSOS; BENEVIDES, 2009, p. 17).

Diante esse quadro, apresentamos algumas reflexões metodológicas decorrentes de uma pesquisa de mestrado em Psicologia que problematizou as estilizações do homoerotismo na velhice entre homens cisgêneros (SANTOS, 2012). Tal pesquisa se fundamentou na cartografia, princípio de exercício do pensamento elaborado por Deleuze e Guattari (2009) e que apresenta pistas importantes nos estudos sobre a subjetividade. Uma das premissas básicas da cartografia é que ela visa acompanhar processos e não representar um objeto (KASTRUP, 2009). Esse foi um ponto importante para a pesquisa, pois se pretendeu problematizar "processos" de estilização do homoerotismo na velhice, e não fornecer modelos explicativos generalizantes que buscassem uma universalidade dessas experiências. Em outras palavras, procurou-se apreender como sujeitos que se autodenominam homossexuais e/ ou experienciam o homoerotismo, vivenciam etapas mais avançadas da vida e quais modos de vida ${ }^{4}$ são possíveis inventar a partir dessa condição existencial. Tendo isso em vista, não se buscou uma verdade sobre a velhice homossexual, ou sobre o sujeito velho homossexual, mas figurações nômades (BRAIDOTTI, 2000) possíveis de serem estilizadas. Assumiu-se, dessa forma, que tanto a

\footnotetext{
${ }^{4} \mathrm{~A}$ noção de modo de vida é aqui tomada tal como foi descrita por Foucault (1981, online) em uma entrevista publicada no jornal Gai Pied, $\mathrm{n}^{\circ} 25$, intitulado "Da amizade como modo de vida": "Um modo de vida pode ser partilhado por indivíduos de idade, estatuto e atividade sociais diferentes. Pode da lugar a relações intensas que não se pareçam com nenhuma daquelas que são institucionalizadas e me parece que um modo de vida pode dar lugar a uma cultura e a uma ética. Acredito que ser gay não seja se identificar aos tracos psicológicos e às máscaras visíveis do homossexual, mas buscar definir desenvolver um modo de vida".
}

velhice como a homossexualidade são passíveis de serem constantemente (re)criadas e (re)inventadas a partir de diversos formas de existencialização.

Isso também implica não considerar que a velhice entre homossexuais pressuponha uma condição ontológica ou que haja "uma velhice homossexual". Isso porque, como Butler (2002, p. 161) sinaliza, “o domínio da ontologia é um território regulamentado: o que se produz dentro dele, o que é dele excluído para que o domínio se constitua como tal, é um efeito do poder". Nesse sentido, se declararmos que existe "uma" velhice homossexual, corremos o risco de cair em explicações generalizantes e que, inevitavelmente, gerarão exclusões. $\mathrm{O}$ que nos interessava, portanto, era como certos discursos produzem "efeitos" ontológicos (BUTLER, 2002), constituindo sujeitos. Na pesquisa, o foco foi pensar como discursos sobre velhice e (homo)sexualidades se confluem e se dobram sobre os sujeitos, e como, a partir destes regimes de subjetivação, podem-se produzir realidades/territórios existenciais, determinadas performatividades e estilísticas de si.

A cartografia busca se desligar de concepções clássicas de ciência, que pressupõem a separação entre objeto e sujeito configurando-os como categorias transcendentais e distintas. $\mathrm{O}$ olhar cartográfico não estabelece essa distinção, pois assume que se trata de figurações históricas em movimentos de afecção permanente e que adquirem significação a partir de determinados regimes de enunciação. Sendo assim, uma pesquisa cartográfica não busca modelos explicativos e representacionais, mas delimitar "problemáticas" acerca de como se dinamiza a constituição do sujeito no "entre forças" do campo social. Segundo Fernández (2008, p. 31), "pensar problemas" seria mais do que aplicar modelos teóricos: demandaria constantes interrogações que façam com que o "invisível opere visibilidade e o impensado se torne enunciável". Assim, "tenta-se sustentar uma tensão, ou seja, manter um incômodo como caução metodológica diante da consolidação de certezas que, enquanto tais, correm o risco de deixar de operar como ferramentas, para instituir regimes de verdade" (FERNÁNDEZ, 2008, p. 31).

O pensamento cartográfico nos parece um princípio pertinente às problematizações feministas e queer, ${ }^{5}$ principais perspectivas que orientam nossas pesquisas sobre

${ }^{5}$ Queer é um termo em inglês que pode significar algo próximo de "esquisito" e "estranho", mas também é uma palavra de insulto e de caráter sexual, próximo ao termo "bicha" ou "viado", no português. Os estudos e/ou pensamentos Queer propõe uma subversão linguística desta palavra, de modo a confrontar os significados culturais pejorativos associados a ela. Trata-se de uma operação política na linguagem que pretende quebrar rede de significados, afirmar os desvios, deixar evidente as hierarquias de poder que perpassam as relações de gênero e de sexualidades, romper com binarismos, questionar o caráter essencialista das identidades e propor uma desconstrução da própria noção de corpo, sexo, gênero e desejo. Os estudos queer, teoricamente, não devem ser tomados como um campo disciplinar, dado sua visão bastante heterodoxa e múltipla (SPARGO, 2006). Apesar de o termo em português não produzir o mesmo efeito subversivo no ato de sua enunciação, no Brasil, e em vários países de língua não inglesa, mantém-se o termo em inglês (queer), argumentando-se que uma possível tradução não daria conta de toda a complexidade linguística da palavra inglesa. Embora seja possível desenvolver uma crítica pós-colonial sobre o fenômeno do tráfico de teorias (da Europa e EUA para o resto do mundo) (COSTA, C., 2012) e o uso da palavra queer em contextos acadêmicos brasileiros, resolvemos mantê-la sem tradução, reconhecendo e afirmando que se trata de um uso problemático e situado de uma palavra. Alguns grupos no Brasil, ainda pouco expressivos, têm arriscado o uso do termo "transviado" como uma alternativa, em português, à palavra queer. Assim, poderíamos falar em "Estudos Transviados", apesar de isso estar longe de ser algum consenso entre pesquisadores/as brasileiros. 
sexualidades e gênero. A crítica à ciência moderna e aos seus pressupostos metodológicos clássicos (neutralidade, imparcialidade, empirismo, racionalismo, objetividade, caráter progressista da racionalidade científica, etc.) também está na base de discussões de muitas teóricas do campo feminista, como Haraway (1995, 2009), Harding (1996), Butler (1998), Braidotti (2000), entre outras. É importante lembrar que as teorias feministas e queer estabelecem diversas rupturas epistemológicas no campo das ciências, produzindo, desse modo, novas concepções de sujeito, outros olhares sobre o social e as subjetividades e uma analítica profunda das relações de poder que permeiam as questões de gênero e sexualidades. Além disso, tais teorias têm se mostrado bastante preocupadas com as questões de interseccionalidade (PISCITELLI, 2008) entre classe social, gerações (DEBERT, 1999; MOTTA, 2002; POCAHY, 2011), raça/etnia e colonialismos (HOOKS, 1989; ANZALDÚA, 2005; BRAH, 2006).

Haraway (1995), por exemplo, ao questionar o pressuposto da objetividade, tão caro à ciência moderna, irá demonstrar que o objetivismo não passaria de retórica que funcionaria dentro de um campo de poder. Nesse sentido, para a autora (HARAWAY, 1995, p. 10) "todo conhecimento é um nódulo condensado num campo de poder agonístico". Que ciência, então, produzir a partir de uma perspectiva feminista? Haraway (1995, p. 15), ao lado de outras teóricas, defende que as práticas de produção de saber devem estar sempre remetidas às suas contingências históricas. Logo, a ciência não pode ser entendida como um saber neutro, tampouco somente como um efeito epistemológico ou uma objetividade transcendente. Ela deve, sim, levantar questões ético-políticas que visem analisar as construções dos significados e dos corpos, as diferenciações e hierarquizações de poder. É dentro dessa concepção tensional de ciência que Haraway (1995, p. 18) irá, por fim, defender uma ciência feminista crítica e sempre paradoxal: a objetividade feminista seria, portanto, sempre uma questão de saberes localizados. Todo saber produzido carrega uma série de produções discursivas locais e datadas, as quais dificilmente poderiam extrapolar em generalizações e/ou em reduções a simples objetos ou estruturas. Com isso, a autora pretende complexificar o campo da ciência, destacando seu aspecto limitado e ao mesmo tempo performativo:

Todas as narrativas culturais ocidentais a respeito da objetividade são alegorias das ideologias das relações sobre o que chamamos de corpo e mente, sobre distância e responsabilidade, embutidas na questão da ciência para o feminismo. A objetividade feminista trata da localização limitada do conhecimento localizado, não da transcendência e da divisão entre sujeito e objeto. Desse modo podemos nos tornar responsáveis pelo que aprendemos a ver (HARAWAY, 1995, p. 21, grifo nosso).

Tornarmo-nos responsáveis por aquilo que dizemos e vemos pressupõe uma implicação imediata com aquilo ou aqueles que temos diante de nós. Feministas e críticos/as da ciência contribuíram enormemente em suspeitar da inércia e passividade de um suposto "objeto" (HARAWAY, 1995, p. 35). Objeto nunca é em si objeto, mas efeito enunciativo e material que afeta e é afetado, produz e é produzido ao mesmo tempo. As perspectivas feministas (que abarcam um complexo de teorizações bastante heterogêneas e instáveis) inspiram diferentes possibilidades epistemológicas e metodológicas, o que evidencia seu potencial multidisciplinar. Os feminismos (sempre no plural) foram importantes correntes que evidenciaram, no meio acadêmico e intelectual, que nossas escolhas epistemológicas e teóricas e nossos paradigmas de pesquisa são sempre escolhas políticas (NARVAZ; KOLLER, 2006).

Em linhas de pensamento muito semelhantes ao de Donna Haraway, Judith Butler, teórica feminista e considerada uma das precursoras da teoria queer, também irá problematizar a questão do saber/poder e suas relações com as políticas identitárias e as formas totalizantes de se descrever o social e os sujeitos. Butler (2003), ao desenvolver uma problematização e a crítica sobre as políticas representacionais e identitárias, apresenta-nos algumas noções de sujeito e de política em suas dimensões contingentes. Inspirada na crítica nietzscheana à substância metafísica do ser, a autora argumenta que as noções modernas de sujeito estão ancoradas em concepções que presumem um caráter substantivo, com atributos essencialistas. Nessas concepções clássicas, o sujeito seria possuidor de uma interioridade substancial a qual, para ser explicada, precisaria de conceitos metafísicos que o deslocaria da história e de seus contextos socioculturais.

Essas noções de sujeito estariam atreladas a uma economia significante masculinista, noção que Butler (2003) toma de Luce Irigaray para argumentar que os significados que damos àquilo que vemos e observamos estão remetidos a significantes falocêntricos e estão, portanto, longe de uma significação neutra e imparcial. Butler, apoiada em pensadores como Lacan, Derrida e Foucault, irá defender que não há sujeitos substantivos ou uma ontologia do ser anterior ao discurso. Aquilo que acreditamos constituir uma realidade transcendente e uma coerência e linearidade interna (de sujeitos, identidades, subjetividade, gênero, sexualidade), seriam efeitos ficcionais que reiteram relações de poder através de atos performativos. Nesse sentido, o ato performativo de nomear ou interpelar algo ou alguém tem efeitos produtivos sobre esse algo ou alguém, o que nos coloca diante da impossibilidade da representação "pura" de um objeto e/ ou sujeito. Butler (1998) salienta a necessidade de nos perguntarmos sobre o processo de construção e significação do sujeito e da política, não caindo em categorias universais as quais, para a autora, seriam formas de imperialismo cultural que só produziriam mais exclusões.

Se não há identidades sexuais e de gênero ancoradas em algum tipo de ontologia metafísica, mas processos performativos de produções identitárias, como sustenta a crítica de Judith Butler, traçar uma cartografia queer, de acordo com Preciado (2008), requer destacar como os discursos e as representações constroem os sujeitos que eles dizem explicar e nomear. Assim, não basta apenas entender, tomando como exemplo nosso tema de pesquisa, como as representações da velhice e da homos- 
sexualidade, que muitas vezes se encerram nos limites identitários dessas categorias, determinam a produção de subjetividade. É preciso acompanhar os movimentos e os processos que se efetivam no plano dos espaços de subjetivação. Uma cartografia queer, portanto,

no propone tanto un análisis en términos de identidad, sino de producción de subjetividad, menos de posición que de movimiento, no tanto de representación como de performatividad, menos en términos de objeto o cuerpo que en términos de tecnologías políticas y de relacionalidad. [...] se tratará de entender la espacialización de la sexualidad, la visibilidad y la circulación de los cuerpos y la transformación de los espacios públicos y privados como actos performativos capaces de hacer y deshacer la identidad $^{6}$ (PRECIADO, 2008, p. 07).

Esses são breves exemplos de como pensadoras feministas e queer colocam em questão problemáticas caras à prática cartográfica, mesmo que as mesmas não façam uso deste conceito, ou não compartilhem os mesmos pressupostos teóricos. Não temos a pretensão de fazer uma discussão exaustiva sobre as possíveis aproximações entre tais perspectivas, mas de apresentar, esboçar e tatear possíveis diálogos. O que há em comum, em muitos momentos, seria uma perspectiva crítica e pós-estruturalista que permeia tanto o pensamento de algumas/ alguns autoras/es feministas e queer, como o de Deleuze e Guattari. A partir dessas aproximações teóricas entre cartografia como exercício de pensamento que visa acompanhar fluxos sociais e as subjetividades, e teorias feministas e queer, é que se foi construindo um olhar e um modo de pesquisar teórica e politicamente orientado.

\section{Algumas pistas cartográficas}

Uma alternativa de análise cartográfica seria acompanhar de que forma as narrativas dos sujeitos e as narrativas coletivas ouvidas enunciam regimes de verdade e formas de resistência. Para Mairesse e Fonseca (2002) a cartografia seria um modo de análise do social e de suas narrações e uma importante ferramenta nas pesquisas em psicologia, pois ela confronta um paradigma hegemônico nesse campo de saber. "Dizer/narrar", "escutar" e "escrever", seriam redes de tradução e de criação de sentidos na cartografia (MAIRESSE; FONSECA, 2002).

A "escuta" do/a pesquisador/a, segundo essas autoras, precisa estar atenta à forma de acolhimento que as narrativas terão durante o processo da fala e de sua análise. Mairesse e Fonseca (2002) alertam que subjacente à escuta de histórias contadas, há o que Foucault (2008) chama de "vontade de saber", que implica ao mesmo tempo em uma "vontade de verdade". Essa busca por uma verdade reflete uma orientação positivista que pretende desvelar um objeto a ser conhecido. A prudência de não cair na armadilha de procurar uma verdade escondida ou oculta nas narrativas durante o seu acolhimento é importan-

\footnotetext{
"não propõe uma análise em termos de identidade, mas de produção de subjetividade, menos de posição, mas de movimento, não tanto de representação quanto de performatividade, menos em termos de objeto ou corpo do que em termos de tecnologias políticas e de relacionalidade. [...] Buscará entender a espacialização da sexualidade, a visibilidade e circulação de corpos e transformação dos espaços públicos e privados como atos performativos capazes de fazer e desfazer a identidade" (tradução nossa).
}

te, pois o/a pesquisador/a, ao invés de dar passagem aos múltiplos sentidos possíveis de uma rememoração, pode passar a atuar numa posição de bloqueador/a dos mesmos. Como diria Foucault (2008, p. 18), essa vontade de verdade tende a exercer uma espécie de pressão e um poder de coerção. Desse modo, bloquear-se-iam, no encontro onde a narrativa se produz, movimentos de devir e de afetos. ${ }^{7}$

A "narrativa" por sua vez, de acordo com as autoras citadas, criaria um espaço de ficção, onde a memória favoreceria a construção de imagens-lembranças num tempo vivido como duração (DELEUZE, 1999). Ora, nesse sentido, ao narrar uma história, o passado se atualiza no presente, ressignificando ambos, possibilitando encontros infinitos e produzindo efeitos de subjetivação. Passado e presente não se situam em planos lineares cronológicos, mas numa coexistência virtual (DELEUZE, 1999). É nesse trabalho de si sobre si que a narrativa (e também a escuta) faz com que possamos acompanhar movimentos do desejo e das subjetividades. Para Mairesse e Fonseca (2002, p. 114) "a repetição deste ato [contar/ escutar] permite compor e recompor a imagem que cada geração tem das anteriores. Aciona-se a reversibilidade do tempo e com este a produção de práticas e afetos".

É importante salientar que, em nossa pesquisa, foram consideradas não apenas as narrativas pessoais que foram faladas pelos informantes que compartilharam suas histórias, mas também as "narrativas coletivas", que circulam no campo social e no território habitado, como se verá mais adiante. Essas últimas não são necessariamente faladas, mas funcionam como efetuadoras de sentidos e sensações produzidos por um coletivo de pessoas. São mais da ordem das afecções, do invisível e indizível, mas que passam a ganhar valor de enunciação a partir de um território potencialmente inventivo, de outras subjetivações, de novos valores estético-corporais e novos desejos. Essas narrativas coletivas apontam também para movimentos de resistências. As narrativas contadas/escutadas foram consideradas dentro daquilo que Passos e Benevides (2009) denominam de políticas da narratividade. Segundo os autores:

podemos pensar a política da narratividade como uma posição que tomamos quando, em relação ao mundo e a si mesmo, definimos uma forma de expressão do que se passa, do que acontece. Sendo assim, o conhecimento que exprimimos acerca de nós mesmos e de mundo não é apenas um problema teórico, mas um problema político (PASSOS; BENEVIDES, 2009, p. 151).

Por fim, a "escrita" (ou o registro) possibilita a materialização de um mapa que se está cartografando. Um mapa, segundo Mairesse (2003), "não está limitado a um espaço-tempo, mas seria um mapa de intensidades, transformável em função da constelação afetiva que o/ se compõe. Por isso, o mapa é devir; ler um mapa é cartografá-lo". É importante salientar, nesse sentido, que a escrita não deve se limitar à representação (como um "dado" autêntico que traduz a realidade), pois o mapa não pode nunca ser capturado, dado o caráter da dina-

${ }^{7}$ Segundo Deleuze (2008, p. 171), os afectos não são sentimentos, são devires que transbordam aquele que passa por eles (tornando-se outro). 
micidade de sua composição. Ele jamais deve ser visto como um simples instrumento mimético, mas sim como um sistema construtivo (ANTONIOLI, 2010). Um mapa é sempre finito, provisório, fugidio, efêmero. Segundo Deleuze e Guattari (2009, p. 22):

O mapa é aberto, é conectável em todas as suas dimensões, desmontável, reversível, suscetível de receber modificações constantemente. Ele pode ser rasgado, revertido, adaptar-se a montagens de qualquer natureza, ser preparado por um indivíduo, um grupo, uma formação social. Pode-se desenhálo numa parede, concebê-lo como obra de arte, construí-lo como uma ação política ou como uma meditação.

Talvez seja diante essa complexidade que devemos reconhecer, habituar-nos e ter intimidade com aquilo que Rolnik (2007) chama de "finito ilimitado". A escrita, os movimentos possíveis de serem apreendidos, o tempo para se contar histórias e a própria cartografia, são limitados em sua contingência temporal, por isso finitos. No entanto, as possibilidades de conexões, afecções, significações que decorrem dos encontros são ilimitadas. "Nunca se chega a um porto de embarque, porto de origem, terra natal. Nem a um porto de desembarque, porto final, terra prometida" (ROLNIK, 2007, p. 76). A escrita se materializou a partir da manutenção de diários de campo que posteriormente se constituíram como material de análise que compuseram os traçados de nossos mapas. Os diários de campo funcionaram como registros de conversas, de afecções, de estranhamentos, de sensações e de percepções sentidas no/pelo corpo. O cartógrafo não procurou por uma representação neutra que silenciasse seus perceptos e afectos, mas sim buscou, na escrita, um modo de expressão daquilo que se passava no campo. Nesse sentido, concordamos com Pozzana e Kastrup (2009, p. 73) que sugerem que:

ao escrever detalhes do campo com expressões, paisagens e sensações, o coletivo se faz presente no processo de produção de um texto. Nesse ponto, não é mais um sujeito pesquisador a delimitar o seu objeto. Sujeito e objeto se fazem juntos, emergem de um plano afetivo. O tema da pesquisa aparece com o pesquisar. Ele não fica escondido, disfarçado ou apenas evocado.

Desse modo, escrever as narrativas pessoais e as narrativas que circulam no campo social, possibilita uma cartografia de agenciamentos coletivos de enunciação, ou seja, uma cartografia de uma multiplicidade de forças (discursivas, afetivas, grupais, eróticas, sexuais, de poder, etc.) que compõem territórios existenciais. Não se trata de individualizar as narrativas e seus agenciamentos, ${ }^{8}$ mas de colocá-los num plano de produção social, de "pinçar" os enunciados das palavras. Não se trata também de reduzir os processos discursivos de assujeitamento e de resistência a um sujeito como ponto de origem, como ressaltam Souza (2003) e Butler (1998) ${ }^{9}$ Deleuze (2005,

\footnotetext{
Segundo Deleuze e Guattari (2009, p. 17), "um agenciamento é justamente o crescimento das dimensões numa multiplicidade que muda necessariamente de natureza à medida que ele aumenta suas conexões". O agenciamento conecta as multiplicidades, assim, configura-se como uma pluralidade de forças que se combinam produzindo uma ficção.

${ }^{9}$ Segundo Butler (1998, p.18), "nenhum sujeito é seu próprio ponto de partida; e a fantasia de que o seja só pode desconhecer suas relações constitutivas refundindo-as como o domínio de uma externalidade contrabalançadora".
}

p. 20) ao discutir Foucault, mostra que "a relação entre enunciado e um sujeito variável constitui ela mesma uma variável intrínseca do enunciado". Assim sendo, um mesmo enunciado pode ter várias posições, vários lugares de sujeito, que não são aspectos de um "eu”, mas derivam do próprio enunciado. Ou seja, um objeto ou um sujeito discursivo (enquanto figuras correlativas às estratégias de saber-poder de um dado dispositivo) não advêm de uma variável extrínseca, tampouco de uma instância individual transcendente, mas é efeito do próprio enunciado. Nesse sentido, não se interpreta a subjetividade (ou a sexualidade, a velhice, etc.) remetendo-a a uma estrutura de signos previamente postulados, mas procura-se uma interpretação das forças que compõem, atravessam e afetam os sujeitos enunciados. Interpretar as forças implica em experimentação, habitar territórios, ser afetado pelos fluxos da realidade que se pretende conhecer, que se pretende acompanhar.

Assim, as experiências da homossexualidade e do envelhecimento foram consideradas como reguladas por efeitos enunciativos de dispositivos históricos (dispositivo-sexualidade (FOUCAULT, 1988) e dispositivo-idade (POCAHY, 2011) e, como tais, estão inscritas em regimes de enunciação, a partir de diferentes estratos históricos. Deste modo, cabe indagarmos sobre os modos de subjetivação produzidos a partir de determinados enunciados, discursos e práticas. Fernández (2008) propõe que direcionemos esses questionamentos a partir de um "campo de problemas da subjetividade" que habilite pensarmos a noção de subjetividade indagando os processos de sua produção, e não através de concepções substancialistas e essencialistas, ou de invariantes universais. Segundo essa autora, um "campo de problema" é atravessado por múltiplas inscrições:

desejantes, históricas, institucionais, políticas, econômicas, etc. [...] este modo de pensar pretende superar os reducionismos necessários às lógicas de objeto discreto que se delimitaram nos momentos fundacionais das ciências humanas [...] para abrir modos de indagação por critérios multireferenciais que dêem outra inscrição à imbricação do "individual" e do "coletivo" nos processos de produção de subjetividade. (FERNÁNDEZ, 2008, p. 28)

Nessa mesma linha de pensamento, Rolnik (2007), seguindo as ideias de Deleuze e Guattari (2010), salienta que a política de produção do social seria a própria produção do desejo. Social e desejo não são dicotômicos, pois são coextensivos. Sendo assim, deve-se estar atento no desenho das cartografias, segundo Rolnik, a dois tipos de olhares: o macropolítico, o qual capta o plano dos territórios, do visível a "olho-nu", das identidades e que se relaciona às linhas duras, e o micropolítico, mais próximo aos movimentos das linhas flexíveis e de fuga, ${ }^{10}$

\footnotetext{
${ }^{10}$ Para Deleuze (1989) as linhas são o que compõem um dispositivo, como já mencionado. Mas elas também podem ser consideradas como fluxos contínuos do campo social, que nos atravessam o tempo todo. Rolnik (2007) considera que essas linhas-fluxos seriam as linhas abstradas do desejo, que o movimenta ou o paralisa. Para esta autora, existiriam basicamente três tipos de linhas: as linhas de fuga, as flexíveis e as duras. Segundo Rolnik, a formação do desejo no campo social acontece a partir do exercício ativo dessas três linhas "sempre emaranhadas, sempre imanentes uma às outras [...] é em seu exercício [das linhas] que se compõem e decompõem territórios, com seus modos de subjetivação, seus objetos e saberes" (ROLNIK, 2007, p. 53).
} 
das multiplicidades. Para a autora, trata-se de um desafio ao cartógrafo reconhecer a "coexistência vigilante entre macro e micropolíticas, díspares, mas complementares e indissociáveis na produção de realidade psicossocial" (ROLNIK, 2007, p. 67, grifo da autora).

Diante dessa complexidade, esboçamos um "roteiro de preocupações" ${ }^{11}$ que foi sendo recriado e redefinido durante a cartografia, tal como sugere Rolnik (2007). Essas questões, num primeiro momento, compuseram um "campo de problemas" sobre o qual o pesquisador-cartógrafo se debruçou no desenvolver da pesquisa. Foram inquietações que, a princípio, foram consideradas como importantes de serem problematizadas a fim de produzir novos questionamentos e fazer operar visibilidades sobre a temática do homoerotismo na velhice.

Portando essas ferramentas teóricas que orientaram o olhar do pesquisador, a imersão no campo se concretizou ao acompanhar algumas experiências, narrativas, modos de vidas e um território de sociabilidade de sujeitos que deslizam por vivências, práticas e desejos homoeróticos ${ }^{12}$ e que estavam, naquele momento, vivenciando a experiência do envelhecimento. ${ }^{13}$

\section{Habitando um território e acompanhando as paisagens}

O problema para o cartógrafo, não é o do falso-ouverdadeiro, nem o do teórico-ou-empírico, mas sim do vitalizante-ou-destrutivo, ativo-ou-reativo. $\mathrm{O}$ que ele quer é participar, embarcar na constituição de territórios existenciais, constituição de realidade (ROLNIK, 2007, p. 66, grifo da autora).

Para acompanhar processos de estilização do homoerotismo na velhice, o pesquisador "habitou" um bar GLS, de Florianópolis, conhecido como "Bar de Ursos", frequentado principalmente por homens mais velhos. Esse bar é visto como fora do mainstream do circuito de sociabilidade GLS na cidade e é pejorativamente atribuído como um espaço "underground", "sujo", de "bicha pobre", "bicha velha", "bicha gorda". De modo geral, é percebido como um lugar desinteressante pelo público mais jovem, que prefere frequentar outras regiões da cidade.

${ }^{11}$ No roteiro de preocupações uma linha de investigação pôde ser traçada no intuito de se apreender uma dimensão macropolítica relativa às produções discursivas e aos enunciados em torno do envelhecimento entre homens homossexuais: quais discursos (in)visibilizam essa categoria? Como o velho homossexual se torna (ou não) objeto e sujeito do saber? Como agenciamentos coletivos de enunciação produzem sistemas regulatórios e formas de inteligibilidades de gênero, sexualidades, corpos e desejos? Num plano micropolítico, algumas outras problemáticas: de que forma os ideais normativos da sexualidade (sustentados pelo sexismo, pela heteronormatividade, pela homofobia pelo falologocentrismo) e da velhice (propagados pelos discursos da mídia, da medicina, dos(as) próprios(as) velhos(as) e de movimentos sociais) se articulam na produção de territórios existenciais marcados pela incorporação de determinadas normas e/ou recusa das mesmas? Quais as formas de (re)invenção de si e de criação de rupturas que escapam às modelizações discursivas/ identitárias homogeneizadoras? A abjeção seria sempre uma condição dos homossexuais velhos? Quais possibilidades estéticas emergem diante essas condições? Até que ponto essas categorias são valoradas e ganham significação na vida de homens gays velhos?

${ }^{12}$ Não necessariamente todos os homens com quem se pôde conversar durante a pesquisa eram homossexuais assumidos. Alguns se consideravam bissexuais, outros heterossexuais que se interessavam por encontros homoeróticos e outros preferiam não se definir em termos de uma identidade sexual específica.

${ }^{13}$ Para uma problematização mais aprofundada sobre as narrativas de si dos informantes de nossa pesquisa, conferir Santos e Lago (2013). Uma discussão mais enxuta sobre o território, corpo e desejo foi publicada nos anais do Congresso Internacional de Estudos sobre a Diversidade Sexual e de Gênero da ABEH, realizado na UFBA, em 2012, sob o título: Porosidades da velhice: experimentações (homo)eróticas de corpos dissidentes (SANTOS; LAGO, 2012).
Nesse sentido, o bar incorpora a imagem de um território a ser evitado, evidenciando o exterior de um limite traçado por algumas normas que regulam lógicas de consumo, mobilidade urbana, estéticas, corpos, erotismos e desejos. O bar é conhecido como um espaço de sociabilidade dos "ursos" onde são realizadas, uma vez por mês, festas direcionadas especificamente para esse público. O pesquisador cartógrafo frequentou o local por quase um ano e meio, quando pôde participar não apenas das "festas especiais" (Encontro dos Ursos), como também de outras ocasiões quando o bar abria para um público mais amplo. O local onde o bar está instalado também é onde reside o proprietário do estabelecimento - um homem de aproximadamente 55 anos - o que possibilitou o pesquisador frequentar o espaço em outros momentos em que não estavam acontecendo as festas, quando se pode ter conversas mais demoradas com o dono do local.

Em minhas incursões ao bar, notei, a partir de minhas experiências pessoais, algumas diferenças nos modos de se estilizar e estetizar expressões da (homo)sexualidade e de gênero em locais de sociabilidade GLS. Corpos que pareciam fugir a um padrão normativo de jovialidade, beleza, moda e até mesmo gosto musical, transitavam pelo espaço desenhando o que para mim parecia uma nova forma de se constituir sujeito dentro de uma "comunidade gay". Alguns "padrões identitários" comumente visíveis em outros espaços mais hegemônicos (estilos de se vestir, gestualidades, gírias, etc.) foram, por mim, pouco vistos e/ou ouvidos. Nesse sentido, o local me pareceu um espaço mais acolhedor àqueles que não se sentem configurados em espaços onde predomina um elogio a uma estética corporal gay considerada "aceitável", eminentemente marcada por atravessamentos de classe social, raça/etnia e geração - ou seja, uma estética muito presente e normalizada entre grupos de classes sociais média e alta, branca e composta majoritariamente por jovens e que geralmente está associada à supervalorização de um corpo "belo" e ideal ("liso", ou seja, sem pelos, musculoso, "na moda" e jovem).

O bar foi considerado como "território" não somente no sentido geográfico e espacial - que se configura numa geografia da cidade e numa relação com um espaço marcado por divisões de classes -, mas também em um sentido mais ampliado, que por vezes pode extrapolar os sentidos "concretos", puramente visíveis e imediatos. Assim, para Guattari e Rolnik (2007, p. 388),

o território pode ser relativo tanto a um espaço vivido, quanto a um sistema percebido no seio do qual um sujeito se sente "em casa". O território é sinônimo de apropriação, de subjetivação fechada sobre si mesma. Ele é o conjunto dos projetos e das representações nos quais vai desembocar, pragmaticamente, toda uma série de comportamentos, de investimentos, nos tempos e nos espaços sociais, culturais, estéticos, cognitivos.

Um território, portanto, pode ser considerado geopolítico e existencial, passível de ser desmontado, capturado, endurecido, flexibilizado. Pode se desterritorializar, quer dizer, desfazer-se numa linha de fuga possibilitando a criação de outros universos de referência, como pode também se reterritorializar, ou seja, se recompor e se fi- 
xar novamente numa modelização dos fluxos e das subjetividades (GUATTARI; ROLNIK, 2007; DELEUZE; GUATTARI, 2010). O bar habitado pôde ser visto como um território onde se configuravam certas modelizações de subjetividade e se potencializavam determinadas estilísticas de si. Nesse caso, corporeidade, amizade, erótico e desejo pareciam ganhar vias de expressão alternativas a outros territórios mais rígidos de sociabilidade, onde algumas pessoas não se sentiriam a vontade para circular.

O bar foi tomado como um território na cidade que dá voz e legitimidade de circulação a corpos que encontram matérias de expressão na exaltação das suas diferenças. $\mathrm{O}$ fato de ser um território que acolhe estéticas que são depreciadas e desvalorizadas pelas mídias, por padrões homogeneizadores de beleza e por outros grupos e espaços de (homo)sociabilidade, faz com que esses corpos, ora inferiorizados, se potencializem, e com que o erótico e o desejo adquiram outros meios a serem percorridos, outras expressividades. Esse território, que emerge escondido e inaudito na paisagem urbana, lembra um palco marginal, uma territorialidade alternativa (PERLONGHER, 2005), onde é possível estabelecer políticas da amizade e inventar outros modos do homoerotismo e do envelhecimento.

O caminho cartográfico de dar visibilidade aos focos de resistência de um território e dos sujeitos que o frequentam, inspira-se na proposição de Foucault (1995, p. 234) segundo a qual, para entendermos as relações de poder, devemos investigar as formas de resistência e as tentativas de dissociar essas relações. Partindo dessa estratégia, para se apreender questões como as hetero/homonormatividades, os processos de produção de corpos abjetos e as hierarquizações a partir dos marcadores etários num cenário de (homo)sociabilidade, o pesquisador em campo tomou como pistas "cenas" do território habitado, "afetos" estéticos e eróticos agenciados no local e as "narrativas" dos interlocutores com quem se pôde conversar, considerando tanto os discursos de resistência, como os normativos. Afirmar a potencialidade de resistência de um território não implica dizer, no entanto, que ele não seja marcado também por linhas duras, por relações de poder e performatividades que, muitas vezes, fazem ressoar discursos homo/heteronormativos e sexistas. O que pretendemos salientar é a natureza multilinear do território, reconhecendo que havia uma dinamicidade de linhas em movimento e não pontos estáticos de poder e resistência. Essas linhas compõem um caráter rizomático, que se atualiza nas relações entre as pessoas ao ampliar as possibilidades de encontros inusitados ( velhos com jovens, ursos com sarados, etc).

A cartografia de tal território de sociabilidade procurava estar atenta às multiplicidades e aos agenciamentos possíveis no local, evitando reduzir o que se experienciava por lá a algum tipo de explicação generalizante e/ou universal. Procurou-se praticar o "princípio de cartografia", como sugerido por Deleuze e Guattari (2009) e evitar a lógica do decalque e da reprodução. Nesse sentido, concordamos que:

Escolher 'cartografar' um território significa [...] renunciar a explicar a multidão de variações 'superficiais' por um único eixo genético, por uma estrutura profunda exclusiva ou por um princípio transcendente, para se situar ao nível da superfície por onde sopra a imanência. Quer se trate do inconsciente, de grupos sociais e políticos, de regiões do mundo ou de conceitos filosóficos, o decalque privilegia sempre o estratos (as entidades constituídas e fixadas em um funcionamento imutável) e os funcionamentos molares (da ordem macroscópica ao invés da microscópica e molecular), os centros instituídos do poder (real ou simbólico) e todos os fenômenos que podem facilmente ser reduzidos a uma causa única e universalmente válida (ANTONIOLI, 2010, p.05)

Em resumo, as pistas gerais seguidas na pesquisa foram: a) habitar um território frequentado principalmente por homens mais velhos que experimentam formas de homoerotismo; b) produzir diários de campo a partir desse território; c) ouvir as narrativas que esses sujeitos têm a contar (seja no próprio campo ou em entrevistas individuais); d) habitar e implicar-se nesse território geográfico e existencial.

A partir das informações construídas no percurso cartográfico pretendeu-se, finalmente, dar visibilidade política e teórica aos modos de vida e aos processos de subjetivação que envolvem a experiência do homoerotismo na velhice. A seguir, são destacadas algumas notas da pesquisa de campo realizada no bar habitado, enfatizando, principalmente, os efeitos que o território de sociabilidade produziu no pesquisador cartógrafo. Desse modo, espera-se tornar visível como o ato da cartografia coexiste com processos de subjetivação que implicam e atravessam o pesquisador.

\section{Sobre encontros de corpos: diferenças e afetações}

Dois homens de idades notavelmente diferentes, que códigos terão para se comunicar? Estão um em frente ao outro sem armas, sem palavras convencionais, sem nada que os tranquilize sobre o sentido do movimento que os leva um para o outro. Terão que inventar de A a Z uma relação ainda sem forma que é a amizade: isto é, a soma de todas as coisas por meio das quais um e outro podem se dar prazer (FOUCAULT, 1981)

“[...] Em um momento da noite eu estava sentado na mesa do bar próxima à mesa de bilhar, tomando uma cerveja. Um homem, que depois me informara ter pouco mais de 50 anos, pediu licença para se sentar comigo. Disse para que se sentasse e começamos uma pequena conversa. Perguntei seu nome, se ele gostava do local e se o frequentava sempre. Falou que se sentia muito à vontade ali, por isso ia de vez em quando. Um

comentário me chamou a atenção: "Mas você é muito novo, o que tá fazendo aqui? Aqui não é lugar pra você, só tem gente velha! Você pode ir em lugar com gente da sua idade...". Respondi que gostava dali, por isso também frequentava o espaço. Percebi um discreto flerte no decorrer da conversa, que logo foi interrompida com a chegada de um amigo que o chamou para conversar e dançar. Essa fala pareceu demonstrar, por parte daquele homem, certo espanto em me ver naquele local, como se 
minha juventude não pudesse habitar sua velhice e viceversa. Seu questionamento não parecia estar baseado numa censura do tipo "esse não é seu lugar, caia fora", mas sim na desestabilização de uma concepção de espaço que compartimentaliza as pessoas a partir de diferenças geracionais. Esse elemento surpresa pareceu decorrer de uma desterritorialização de universos de referência que nos afetou naquele instante no qual nossas diferenças visiveis nos inseria numa outra politica possivel [...]"

(trecho do diário de campo)

Quais encontros possíveis entre mim, um pesquisador jovem, gay, pós-graduando, homem cisgênero, magro, de estatura baixa, moreno claro, psicólogo (entre outras máscaras e rostos possíveis, difíceis de serem listados) e homens também gays ou bissexuais, mais velhos que eu, com outra estética corporal, às vezes gordos, grisalhos ou não, com formas de se vestir e gostos diferentes, das mais variadas classes sociais?

Antes de problematizar o que podem esses encontros, é preciso narrar um pouco sobre meu próprio interesse de pesquisa. Porque pesquisar velhos? E velhos gays? E as subjetividades de velhos gays? E corpos de velhos gays? Desde quando entrei no mestrado, ao anunciar esse tema de pesquisa, muitos diziam algo como "Nossa, que tema interessante, mas não é meio triste esse assunto?", ou então: "Mas porque você quer pesquisar isso, que coisa mais monótona!" e ainda: "Só uma bicha nova mesmo pra pesquisar algo tão difícil, que é o envelhecer". Alguns mais otimistas diziam: "Que tema bonito, realmente é preciso mais estudos sobre esse tema", "Que legal, quero acompanhar sua pesquisa, pois me identifico com ela!". Alguns homens velhos com quem conversei, fora do meio acadêmico, falavam, por sua vez: "Mas o que você quer descobrir? O que quer provar?"; "Gays envelhecem de forma diferente?"; "Mas não há diferença entre envelhecer sendo gay ou não, as doenças são as mesmas!'. Esses comentários, por si, já podem dizer muitas coisas, mas o que mais chama a atenção talvez seja o fato de que a velhice ainda é um grande tabu, um grande medo. Com ela, os fantasmas da finitude da vida, da solidão e da transformação do corpo parecem ganhar evidência. Por mais que muitos entendam que grande parte do que pensamos sobre a velhice sejam meros estereótipos e fantasias, ainda parecemos apresentar certa aversão ao tema, seja pelo uso de eufemismos, sarcasmo, chiste, ironia, entre outros recursos da linguagem que tentam afastar da consciência um tema que incomoda. E de fato incomoda, porque vivemos numa sociedade onde os corpos que importam ainda são aqueles que são produtivos, idealmente perfeitos em sua máxima eficácia. Ainda são aqueles da ótima saúde, que respondem a um controle ideal das populações, que mimetizam formas estéticas midiáticas, supervalorizando-as, consumindo e alimentando certas parcelas do mercado. Corpos inseridos numa biopolítica - ou como diria Foucault (1988), numa política que toma a própria vida e sua potência como alvo de gestão e controle.

Fractal, Rev. Psicol., v. 27 - n. 2, p. 95-106, 2015
Portanto, onde me encaixo como pesquisador e sujeito nisso tudo? A resposta, aparentemente, não é difícil: sou gay e vou envelhecer e, de certa forma, talvez tenha sido capturado por esses fantasmas imaginários coletivos sobre velhice e o que é envelhecer sendo gay. Além disso, sou atravessado por processos de subjetivação semelhantes aos dos informantes da pesquisa. Experiencio igualmente certas modelizações de subjetividade, estilizo performatividades de gênero e sexuais, cristalizo-me em algumas identidades ao mesmo tempo em que tento fugir de outras, circulo por meios sociais específicos, sou atravessado pela heteronormatividade e suas consequências, como a homofobia, injúrias, etc. Também sou interpelado por diversas forças que passam a marcar meu corpo, minha subjetividade, meus arranjos identitários, mas também que me estimulam, por vezes, a escapar de certas armadilhas totalizantes. Assim, a velhice e a homossexualidade (e a velhice entre homossexuais) passam a ganhar interesse pessoal e a se constituir como uma questão existencial e de pesquisa, uma vez que também estou imerso nesse mesmo regime discursivo complexo, polivalente e contraditório, que me constitui e me faz sujeito. Mesmo não vivendo ainda de fato (ou pelo menos cronologicamente) a experiência do envelhecimento, há uma velhice que me habita, um velho-em-mim (devir-velho?) que se inquieta com tal questão e com as consequências subjetivas, políticas e sociais que ela acarreta. Há ainda o fantasma da "velhice homossexual", mitificado e caricaturizado pejorativamente na figura da "bicha velha e solitária", que ronda meu imaginário e o dos meus semelhantes.

Diante de todo esse imaginário que circula no campo social sobre o envelhecimento (a maioria das vezes negativo, quando não reinventado pelo discurso da terceira idade e da velhice medicalizada e vigiada), passei a me interrogar, em meio a esse mar de discursos e práticas sociais que dão contorno aos sujeitos, sobre onde a vida pede passagem, onde se reinventa? De que maneiras os indivíduos são chamados a se constituir como sujeitos éticos (FOUCAULT, 1984)? Como pensar, a partir desse contexto, a demanda ética da subjetivação, ou "o que estamos fazendo de nós mesmos", como Cardoso Jr. (2005) ao lembrar Foucault? Essas perguntas ajudaram a pensar sobre o que podem os encontros entre mim e as pessoas com quem pesquisei. Foi nos encontros com esses sujeitos marcados por uma materialidade que denuncia uma idade cronológica e por uma forma de viver um desejo ainda considerado, em alguns contextos, como marginal, que fui percebendo movimentos de estilização da vida, de criação e resistência às várias formas de normatividades encontradas nas relações sociais.

Mas, retomando a pergunta inicial e colocando-a de outra forma, o que acontece quando uma pessoa com "minhas" marcas circula por um território como o bar frequentado? Às vezes sentia-me um estranho, pois era um dos poucos jovens de um ambiente onde homens mais velhos estavam para conversar, divertir-se e exercitar certas políticas do prazer, do corpo e da amizade. Em alguns momentos não me sentia muito à vontade para entrar em uma roda de conversa de amigos, pois alguns 
grupos não davam abertura: estavam ali simplesmente para se divertir com seus colegas. Para mim, as diferenças geracionais foram, desde o começo, algo muito marcante, o que me fazia, às vezes, parecer um estrangeiro num ambiente de diversão. Outras pessoas e grupos, ao contrário, mostravam-se bastante receptivos a uma interação, independentemente de questões etárias.

Havia, ainda, outra marca que meu corpo expressava naquele ambiente e que facilitava e estimulava vários encontros: a possibilidade de eu ser um jovem que sente atração por homens mais velhos e/ou ursos ou, como diriam as categorias nativas, de eu ser um Chaser ou Hunter ( respectivamente, perseguidor e caçador), Bear-lover (amante de urso), ou simplesmente um "cara que curte coroas ou homens maduros". Esses atributos a mim conferidos muitas vezes estimulavam aproximações onde flertes e cantadas eram inevitáveis. Em nenhum momento me senti desconfortável com essas situações, as quais eram facilmente contornáveis entre conversas, cervejas e histórias sobre nossas vidas. Tenho a impressão de que, naquele espaço, conversas mais longas e intimistas eram muito valorizadas, o que facilitava a ampliação dos contatos.

O fato de ser interpelado como Chaser e estar habitando um território onde circulava certo elogio à estética considerada "não erótica" pelas lógicas normativas que produzem as materialidades dos corpos (vistas na mídia e em outros espaços de sociabilidade) foi produzindo em mim um novo olhar sobre as possibilidades eróticas, estéticas e éticas que um corpo pode expressar. Novos agenciamentos se estabeleciam entre meu corpo, ressignificando padrões estéticos de beleza e expandindo as possibilidades de conexões com outros corpos. Penso que tais encontros proporcionaram a ampliação dos meus universos de referência (GUATTARI, 1992), de modo que fui experimentando e exercitando outro olhar àqueles corpos que em outros contextos são depreciados, moralizados e inferiorizados (os corpos velhos e/ou gordos e/ ou "peludos"). Essa experiência possibilitou que o meu olhar e desejo escapassem de certos padrões de repetição modelados por normas e ideais. Ao ampliar universos de referência passei a ser afetado pela possibilidade de erotizar outros corpos, de enxergar sensualidades onde antes parecia existir "apenas" mais um corpo. Mas não só isso: passei também a conviver com uma heterogeneidade de formas de expressar o homoerotismo e a amizade. Um universo que antes me escapava, passava a recompor formas de interação, (re)singularizava-me e possibilitava novas matérias de expressão (GUATTARI, 1992). É o desejo, em sua dimensão produtiva (DELEUZE; GUATTARI, 2010) que percorria os meios e produzia formas estéticas de subjetivação.

Os encontros e as afecções são dimensões valiosas numa cartografia. A capacidade de afetar e ser afetado traduz os corpos em encontros, constituindo um plano de imanência onde as materialidades não são definidas como substâncias, mas como modos, relações de velocidade e lentidão, intensidades de afetação, potência de agir (ou não agir). No plano de consistência (ou imanência), um “corpo só se define por afetos e movimentos lo- cais ou velocidades diferenciais" (PEIXOTO JUNIOR, 2008a, p. 138). A partir dessa perspectiva, a relação do meu corpo com o(s) corpo(s) no/do território não foi pensada como neutra, mascarada de objetividade. Para Peixoto Junior (2008a, p. 146):

Para que haja comunicação entre corpos, faz-se necessário um fundo afetivo: desposamos ritmos emocionais, através da voz, do olhar, da expressividade de outrem, e isso significa que eles se escrevem no espaço da minha abertura ao outro. E esse espaço é, antes de mais, o espaço da pele. Quando compreendo tal expressão facial, é porque o meu rosto desposa e se "plasma" ao ritmo que a anima. É propriamente um processo de devir-outro que ocorre então.

Era preciso abrir o corpo, disponibilizar um corpo intensivo (ou vibrátil) para encontros que flexibilizavam barreiras segmentárias. Embarcando num território onde corpos velhos, gordos, jovens, coroas, ursos e maduros se misturavam, foi possível me deixar afetar por devires outros: devir-velho, devir-urso, devir-erótico. Ora, nada mais pertinente numa pesquisa sobre sexualidade do que o encontro com máquinas desejantes que produzem essas outras sensibilidades, essas outras porosidades do corpo e do desejo. Concordando com Peixoto Junior (p. 170, 2008b), "[...] qualquer aproximação da sexualidade com fenômenos físicos, fluidos e fluxos, matérias e partículas, parece mais adequada do que a sua redução ao pequeno e lamentável segredo familialista edipiano". O erótico e o desejo puderam, portanto, ser pensados em sua dimensão produtiva, maquínica e em relações de multiplicidade.

A seguir, transcrevo uma parte do meu diário de campo, onde relato umas das minhas primeiras impressões sobre as relações das pessoas no bar e minha inserção no mesmo:

Em mim, um estranhamento me percorre de forma agradável: "senhores", "homens maduros", vestidos ao estilo social, pessoas que, em outros ambientes, facilmente passariam por heterossexuais ou por pessoas "assexuadas" devido à idade, trocam afetos, beijos e abraços. Alguns códigos de masculinidades são evidentemente flexibilizados e as relações entre gênero e sexualidade se apresentam como possíveis de serem reinventadas de forma não tão linear. Uma rígida demarcação geracional também, nesse contexto, parece não ter muita importância. Velhos, "maduros", jovens, todos se relacionam e demonstram afetos entre si, sem que a idade seja necessariamente uma forma de classificação depreciativa. (trechos do diário de campo)

Fui percebendo que a territorialidade inventada no bar abria um campo de virtualidade explorada no cenário urbano e concretizada num espaço físico, numa dimensão molecular onde esses acontecimentos irrompem. Nesse sentido, sinto-me falando não mais apenas daquela cidade das belas paisagens naturais, mas de uma cidade que comporta virtualidades, que possibilita novos campos de possíveis, de experimentações do corpo e do prazer e de modos de vida singulares. Uma Cidade Subjetiva, como chamou Guattari (1992). Pelbart (2000) nos lembra que a subjetividade para Guattari não significa interioridade, mas estaria alocada sob o signo da exterioridade. Cidade e subjetividade, portanto, seriam "exterioridades por excelência”. O autor destaca, no entanto, que para traçar- 
mos trajetos exploratórios na urbe, devemos habitar essa exterioridade, uma virtualidade possível de movimentos de afecção. Para isso, é preciso tentar escapar das serialidades que os espaços urbanos geralmente nos impõem e que automatizam nossos percursos, olhares, gestos e paralisam nossas subjetividades (GUATTARI, 1992). Segundo Pelbart (2000, p. 45),

O desafio consistiria em livrar-se do pseudo-movimento que nos faz permanecer no mesmo lugar, e sondar que tipo de meio uma cidade ainda pode vir a ser, que afetos ela favorece ou bloqueia, que trajetos ela produz ou captura, que devires ela libera ou sufoca, que forças ela aglutina ou esparze, que acontecimentos ela engendra, que potências fremem nela e à espera de quais novos agenciamentos.

Penso que o meu encontro com o bar habitado foi um efeito não só de uma busca por um "campo de pesquisa", mas de uma abertura e uma implicação com novos caminhos na paisagem de Florianópolis, para além daqueles já conhecidos. A partir dessa perspectiva - que enxerga a cidade como um lugar da alteridade e de fluxo - , que reconheci a possibilidade de existência de um estabelecimento como o que frequentei durante os meus percursos.

A cartografia, como perspectiva metodológica em pesquisa sobre sexualidades, funcionou como um recurso disponível importante, tanto como problematização epistemológica, quanto problematização da prática do pesquisar. As aproximações entre os pensamentos cartográficos, feministas, nômades e queer mostram-se como potentes caixas de ferramentas nos estudos sobre desejo, sexualidade, corpo e subjetividade. As pistas esboçadas neste texto são meras linhas que expressam um percurso, um pensamento desenvolvido a partir de um ato de pesquisa. Novas conexões podem ser traçadas, outras sensibilidades percebidas, mais cartografias desenhadas.

\section{Referências}

ALVAREZ, J.; PASSOS, E. Cartografar é habitar um território existencial. In: PASSOS, E.; KASTRUP, V.; ESCÓSSIA, L. da. (Org.). Pistas do método da cartografia: pesquisa-intervenção e produção de subjetividade. Porto Alegre: Sulina, 2009. p. 131149.

ANTONIOLI, M. Singularités cartographiques. TRAHIR, [S.1.], première année, août 2010.

ANZALDÚA, G. La conciencia de la mestiza: rumo a uma nova consciência. Rev. Estud. Fem., Florianópolis, v. 13, n. 3, p. 704-719, set./dez. 2005. Disponível em: <http://www.scielo.br/ pdf/ref/v13n3/a15v13n3.pdf>. Acesso em: 25 set. 2011. http:// dx.doi.org/10.1590/S0104-026X2005000300015.

BRAH, A. Diferença, diversidade, diferenciação. Cadernos Pagu, Campinas, n. 26, p. 329-376, jan.-jun. 2006.

BRAIDOTTI, R. Sujetos nômades: corporización y diferencia sexual en la teoría feminista contemporânea. Buenos Aires: Paidós, 2000.

BUTLER, J. Fundamentos contingentes: o feminismo e a questão da "pós-modernismo". Cadernos Pagu, Campinas, n. 11, p. 11-42, 1998.

BUTLER, J. Como os corpos se tornam matéria (entrevista com
Judith Butler feita por Baukje Prins e Irene Costera Meijer). Revista Estudos Feministas, Florianópolis, v. 10, n. 1, p. 155167, jan. 2002.

BUTLER, J. Problemas de gênero: feminismo e subversão da identidade. Tradução de Renato Aguiar. Rio de Janeiro: Civilização Brasileira, 2003.

CARDOSO JUNIOR, H. R. Foucault e Deleuze em coparticipação no plano conceitual. In: RAGO, M.; ORLANDI, L. B. L.; VEIGANETO, A. (Org.). Imagens de Foucault e Deleuze: ressonâncias nietzscheanas. Rio de Janeiro: DP\&A, 2005. p. 185-197.

COSTA, C. de L. Feminismo e tradução cultural: sobre a colonialidade do gênero e a descolonização do saber. Portuguese Cultural Studies, Utrecht, v. 4, p. 41-65, 2012.

COSTA, J. F. A inocência e o vício: estudos sobre o homoerotismo. Rio de Janeiro: Relume-Dumará, 1992.

DEBERT, G. G. A reinvenção da velhice: socialização e processos de reprivatização do envelhecimento. São Paulo: Universidade de São Paulo: FAPESP, 1999.

DELEUZE, G. O que é um dispositivo? Tradução de Ruy de Souza Dias e Hélio Rebello, 2001, a partir do texto: DELEUZE, G. Qu'est-ce qu'un dispositif? In: Michel Foucault philosophe. Rencontre internationale. Paris, 1989.

DELEUZE, G. Bergsonismo. Tradução de Peter Pál Pelbert. São Paulo: Editora 34, 1999.

DELEUZE, G. Foucault. São Paulo: Brasiliense, 2005.

DELEUZE, G. Conversações. Tradução de Peter Pál Pelbert. São Paulo: 34, 2008.

DeleuZE, G.; GUATTARI, F. Mil Platôs: capitalismo e esquizofrenia. Rio de Janeiro: Editora 34, 2009. v. 1.

DELEUZE, G.; GUATTARI, F. O Anti-Édipo: capitalismo e esquizofrenia I. Tradução de Peter Pál Pelbert. São Paulo: 34, 2010.

FERNÁNDEZ, A. M. Las lógicas colectivas: imaginários, cuerpos y multiplicidades. 2. ed. Buenos Aires: Biblos, 2008.

FOUCAULT, M. Da amizade como modo de vida. Entrevista de Michel Foucault a R. de Ceccaty, J. Danet e J. Le Bitoux. Gai Pied, n. 25, p. 38-39, abr. de 1981. Tradução de Wanderson Flor do Nascimento. Disponível em: <http://psicanaliselacaniana. blogspot.com.br/2009/08/da-amizade-como-modo-de-vida. html>. Acesso em: 12 jun. 2013.

FOUCAULT, M. História da sexualidade: o uso dos prazeres. São Paulo: Graal, 1984. v. 2.

FOUCAULT, M. História da sexualidade: a vontade de saber. São Paulo: Graal, 1988. v. 1.

FOUCAULT, M. O sujeito e o Poder. In: DREIFUS, H.C; RABINOW, P. Michel Foucault, uma trajetória filosófica: para além do Estruturalismo e da Hermenêutica. Rio de Janeiro: Forense Universitária, 1995. p.232-239.

FOUCAUlT, M. A ordem do discurso. São Paulo: Loyola, 2008.

FOUCAULT, M. Outros Espaços (conferência). In: Ditos \& Escritos. 2. ed. Rio de Janeiro: Forense Universitária, 2009. v. 3.

GUATTARI, F. Caosmose: um novo paradigma estético. 
Tradução de Ana Lúcia de Oliveira e Lúcia Cláudia. São Paulo: Editora 34, 1992.

GUATTARI, F.; ROLNIK, S. Micropolítica: cartografias do desejo. 8. ed. Petrópolis, RJ: Vozes, 2007.

HARAWAY, D. Saberes localizados: a questão da ciência para o feminismo e o privilégio da perspectiva parcial. Cadernos Pagu, Campinas, n. 5, p. 07-41, 1995.

HARAWAY, D. Manifesto ciborgue: ciência, tecnologia e feminismo socialista no final do século XX. In: HARAWAY, D.; KUNZRU, H.; TADEU, T. (Org.). Antropologia do ciborgue: as vertigens do pós-humano. Belo Horizonte: Autêntica, 2009. p. 33-118.

HARDING, S. Ciencia y feminismo. Madri: Morata, 1996.

HENNING, C. E. Paizões, tiozões, tias e cacuras: envelhecimento, meia idade, velhice e homoerotismo masculino na cidade de São Paulo. Tese (Doutorado em Antropologia Social)-Universidade Estadual de Campinas, Campinas, SP, 2014.

HOOKS, B. Talking back: thinking feminist, thinking black. Boston, MA: South End Press, 1989.

KASTRUP, V. O funcionamento da atenção no trabalho do cartógrafo. In: PASSOS, E.; KASTRUP, V.; ESCÓSSIA, L. da. Pistas do método da cartografia: pesquisa-intervenção e produção de subjetividade. Porto Alegre: Sulina, 2009. p. 32-51.

NARVAZ, M. G.; KOLLER, S. H. Metodologias feministas e estudos de gênero: articulando pesquisa, clínica e política. Psicologia em Estudo, Maringá, v. 11, n. 3, p. 647-654, set./ dez. 2006.

MAIRESSE, D. Cartografia: do método à arte de fazer pesquisa In: FONSECA, T. M. G.; KIRST, P. G. (Org.). Cartografias e devires: a construção do presente. Porto Alegre: UFRGS, 2003. p. 259-272.

MAIRESSE, D.; FONSECA, T. M. G. Dizer, escutar, escrever: redes de tradução impressas na arte de cartografar. Psicologia em Estudo, Maringá, v. 7, n. 2, p. 111-116, jul./dez. 2002.

MOTA, M. P. Homossexualidade e envelhecimento: algumas reflexões no campo da experiência. SINAIS - Revista Eletrônica - Ciências Sociais, Vitória, n. 06, v. 1, p. 26-51, dez. 2009.

MOTTA, A. B. da. Envelhecimento e sentimento do corpo. In: MINAYO, M. C. de S.; COIMBRA, C. E. A. Jr. (Org.). Antropologia, saúde e envelhecimento. Rio de Janeiro: FIOCRUZ, 2002. p.37-50.

PASSOS, E.; BENEVIDES, R. Por uma política da narratividade. In: PASSOS, E.; KASTRUP, V.; ESCÓSSIA, Liliana da. Pistas do método da cartografia: pesquisa-intervenção e produção de subjetividade. Porto Alegre: Sulina, 2009. p. 150-171.

PAIVA, C. Corpos/Seres que não importam? Sobre homossexuais velhos. Revista Bagoas, Natal, v. 3, n. 4, p. 191208, jan./jun. 2009.

PEIXOTO JUNIOR, C. A. O corpo intensivo: notas para uma concepção não-representacional. In: Singularidade e subjetivação: ensaios sobre clínica e cultura. Rio de Janeiro: 7Letras / PUC-Rio, 2008a. p. 134-151.

PEIXOTO JUNIOR, C. A. A multiplicidade sexual das máquinas desejantes e seus destinos. In:__. Singularidade e subjetivação: ensaios sobre clínica e cultura. Rio de Janeiro: 7Letras / PUC-Rio, 2008b. p. 167-186.
PELBART, P. P. A vertigem por um fio: políticas da subjetividade contemporânea. São Paulo: Iluminuras, 2000.

PERLONGHER, N. Territórios Marginais. In: GREEN, J. N.; TRINDADE, R. (Org.). Homossexualismo em São Paulo e outros escritos. São Paulo: UNESP, 2005. p. 263-290.

PISCITELLI, A. Interseccionalidades, categorias de articulação e experiências de migrantes brasileiras. Sociedade e Cultura, v. 11, n. 2, p. 263-274, jul./dez. 2008.

POCAHY, F. A. Entre vapores e dublagens: dissidências homo/ eróticas nas tramas do envelhecimento. Tese (Doutorado em Educação)-Universidade Federal do Rio Grande do Sul, Programa de Pós-Graduação em Educação, Porto Alegre, RS, 2011.

POZZANA, L.; KASTRUP, V. Cartografar é acompanhar processos. In: PASSOS, E.; KASTRUP, V.; ESCÓSSIA, L. Pistas do método da cartografia: pesquisa-intervenção e produção de subjetividade. Porto Alegre: Sulina, 2009. p. 5275.

PRADO-FILHO, K. Michel Foucault: uma história política da verdade. Florianópolis: Insular, 2006.

PRECIADO, B. Cartografías queer: el flâneur perverso, la lesbiana topográfica y la puta multicartográfica o como hacer una cartografia zorra con Anne Sprinkle, 2008. Disponível em: <http://artilleriainmanente.blogspot.com.br/2012/04/ cartografias-queer-beatriz-preciado.html $>$. Acesso em: 7 junho 2015.

ROLNIK, S. Cartografia sentimental: transformações contemporâneas do desejo. São Paulo: UFRGS, 2007.

SANTOS, D. K. Modos de vida e processos de subjetivação na experiência de envelhecimento entre homens homossexuais na cidade de Florianópolis/SC. 2012. Dissertação (Mestrado)Universidade Federal de Santa Catarina, Centro de Filosofia e Ciências Humanas. Programa de Pós-Graduação em Psicologia, Florianópolis, 2012.

SANTOS, D. K.; LAGO, M. C. de S. Porosidades da velhice: experimentações (homo)eróticas de corpos dissidentes. In: CONGRESSO INTERNACIONAL DE ESTUDOS SOBRE A DIVERSIDADE SEXUAL E DE GÊNERO DA ABEH, 6., 2012, Salvador. Anais... Salvador: UFBA, 2012. v. 1, n. 1.

SANTOS, D. K.; LAGO, M. C. de S. Estilísticas e estéticas do homoerotismo na velhice: narrativas de si. Sex., Salud Soc. (Rio J.), Rio de Janeiro, n. 15, p. 113-147, dez. 2013.

SIMÕES, J. A. Homossexualidade masculina e curso da vida: pensando idades e identidades sexuais. In: PISCITELLI, A.; GREGORI, M. F.; CARRARA, S. (Org.). Sexualidade e saberes: convenções e fronteiras. Rio de Janeiro: Garamond, 2004. p. 415-447.

SOUZA, P. Resistir, a que será que se resiste? O sujeito feito fora de si. Linguagem em (Dis)curso, Tubarão, v. 3, Número Especial, p. 37-54, 2003.

SPARGO, T. Foucault e a teoria queer. Rio de Janeiro: Pazulin, 2006.

Recebido em: 16 de julho de 2013 Aceito em: 03 de dezembro de 2014 